\title{
Numerical simulation of seawater intrusion in Manukan Island, East Malaysia.
}

\begin{abstract}
Purpose - This paper aims to define the current and potential extent of seawater intrusion in Manukan Island under different scenarios of varying recharge and pumping rates. The calibrated model was also used to predict the extent of seawater intrusion in low lying area of Manukan Island for two years with all conditions assumed to remain the same as those in December 2009. Design/methodology/approach - Different scenarios of varying recharge and pumping rates based on threats received by Manukan Island were investigated. El-Nino events and overpumping are represented by varying recharge and pumping rates. Simulation was done using SEAWAT-2000, the latest modeling software available in groundwater modeling that couples flow and transport together. Findings - The seawater-freshwater mixing ratio moves landwards after two years of simulation in Scenario 1. In order to control overpumping in this study area, Scenario 2 has resulted in backward movement of the 1.4 percent seawater-freshwater mixing ratio toward the coast after two years of prediction. The current contamination of the coastal aquifers by seawater intrusion will be more severe with an impact of El-Nino events on groundwater resources depletion in Scenario 3. Reductions of pumping and recharge rates in Scenario 4 have worsened the seawater intrusion problem. With the aid of artificial recharge in Scenario 5, highest hydraulic heads and lowest chloride concentration were observed. Practical implications - The sustainable groundwater management selected for Manukan Island's current situation will be Scenario 2. In view of the effects of El-Nino events in the future, Scenario 5 can be implemented to restore groundwater resources. The numerical model has showed the groundwater condition during El-Nino events and overpumping illustrated that simulation modeling is an excellent tool to understand the behavior and management of an aquifer system. The output of simulation modeling via numerical model provides a framework toward groundwater management. Thus, current study output with similar approach which will restore groundwater (artificial recharge and reduction of pumping rate) can be applied in other small islands of similar hydrogeological condition and stresses for the purpose of groundwater resource protection.
\end{abstract}

Keyword: Seawater intrusion; Groundwater modelling; SEAWAT-2000; Recharge rate; Pumping rate; Environmental management; Malaysia. 